\title{
Thriving or Surviving Emergency Remote Teaching Necessitated by COVID-19: University Teachers' Perspectives
}

\author{
Benjamin Luke Moorhouse $^{1}$ (1) $\cdot$ Lucas Kohnke $^{2}$
}

Accepted: 2 April 2021/Published online: 15 April 2021

(C) De La Salle University 2021

\begin{abstract}
COVID-19 has forced universities around the world to suspend in-person teaching and adopt emergency remote teaching (ERT). To compensate for the suspension of in-person teaching, many universities mandated that teachers utilise video-conferencing software (VCS) to deliver synchronous online lessons conducted through VCS. This study explored the impact of ERT and the requirement to teach synchronously online through VCS on the motivation of university teachers at a major university in Hong Kong. In-depth interviews were conducted with nine teachers who had completed a full semester of ERT. The findings suggest that the teachers fell into two distinct groups. Teachers in one group $(n=5)$ seemed to thrive, reporting mainly positive effects of ERT on their motivation, while the others $(n=4)$ seemed to be just surviving, reported mainly negative effects. For members of the "thriving" group, the semester reinvigorated their teaching and provided them with new skills; members of the "surviving" group, by contrast, questioned their ability to teach, found it hard to build a rapport with learners, felt isolated, and struggled to find job satisfaction. The study concludes with a discussion of measures that could help university teachers to maintain their motivation during online instruction.
\end{abstract}

Benjamin Luke Moorhouse

blmoorhouse@hkbu.edu.hk

1 Department of Education Studies, Hong Kong Baptist University, Academic \& Administration Building, Baptist University Road Campus, Hong Kong, China

2 English Language Centre, The Hong Kong Polytechnic University, Hong Kong, China
Keywords Teacher motivation .

Emergency remote teaching - Self-determination theory * Synchronous online teaching $\cdot$ COVID-19

\section{Introduction}

COVID-19 has forced universities around the world to suspend in-person teaching to minimise person-to-person physical contact and the spread of the virus. Accordingly, online-only modes of instruction, known collectively as emergency remote teaching (ERT), have been adopted (Hodges et al., 2020). Unlike courses specifically designed for online delivery, ERT refers to courses originally designed for in-person instruction that have been modified for online instruction due to emergency situations (Hodges et al., 2020). ERT presented new and unique challenges for teachers who were required to adapt rapidly to the dramatically different digital teaching and learning environment (Xie et al., 2019). Hong Kong, the context of this current study, was one of the first places to be directly affected by COVID-19 with in-person classes in all higher education institutions suspended in late January 2020 and teachers required to teach online for the spring semester (Chan, 2020).

Hong Kong universities have adopted various modes of blended learning for several years. It is common for inperson courses to be supplemented with asynchronous resources delivered through a Learning Management System (LMS) (Deng \& Tavares, 2013). However, to compensate for the suspension of in-person lessons, necessitated by COVID-19, many universities, including the one under study, mandated that teachers utilise videoconferencing software (VCS) to deliver synchronous online lessons (Crawford et al., 2020). Widespread use of 
synchronous online teaching has only recently been made possible due to technological advancement and the widening availability of high-speed internet (Martin \& Parker, 2014). This mode of instruction was new to many university teachers and students in Hong Kong (Moorhouse, 2020) and the wider global higher education sector (Metscher et al., 2020).

Due to the rapid implementation or ERT, little research has explored the impact of adapting to ERT and, in particular, the requirement to teach synchronously onlineincluding working from home in social isolation (American Psychological Society, 2020)—on university teachers' motivation, well-being, and practice (Wong \& Moorhouse, 2020).

It is important to explore how university teachers have been coping with the changes caused by COVID-19 and the shift to ERT and synchronous online teaching, in particular regarding their motivation to teach. Teachers' motivation can impact the quality of their teaching, mental health, and long-term commitment to teaching as well as students' learning (Carson \& Chase, 2009; Dörnyei \& Ushioda, 2011; Ryan \& Deci, 2020).

This current study, using self-determination theory (SDT) (Ryan \& Deci, 2000, 2020) as an analytical framework, explores the impact COVID-19 and the experience of ERT, including the requirement to conduct synchronous online lessons, had on a group of English for academic purposes (EAP) teachers at a major university in Hong Kong. An understanding of how teacher motivation has been impacted can assist university leaders in identifying the best ways to cope with COVID-19 and ERT and, therefore, provide a more conducive and sustainable learning environment for students. Furthermore, although teachers' motivation to teach online has been explored in the research literature (e.g., Doo et al., 2020; Wasilik \& Bolliger, 2009), these studies have examined courses delivered primarily asynchronously, not synchronously. The utilisation of synchronous online teaching in higher education is likely to grow beyond the pandemic, due to the opportunity it provides for students and teachers to interact in real-time while maintaining the flexibility of online learning (Martin \& Parker, 2014). The potential growth in synchronous online teaching makes it critically important to understand better teachers' motivation to teach through this mode.

\section{Teacher Motivation}

Teacher motivation has received considerable attention in educational research in recent years (Dörnyei \& Ushioda, 2011; Ryan \& Deci, 2000, 2020). Motivation is a complex psychological concept, so defining it in the context of university educators has been problematic. However, scholars have tended to relate teacher motivation to the reasons that individuals choose to teach and remain in the profession and the intrinsic and extrinsic factors affecting the effort that a teacher expends on the job (Han \& Yin, 2016). Studies have concluded that teacher motivation is "primarily derived from the intrinsic value of teaching" (Han \& Yin, 2016, p. 7).

To help understand the factors that facilitate or undermine an individual's motivation and psychological wellbeing, Ryan and Deci (2000, 2020) propose the SDT. Ryan and Deci (2020) suggest that "SDT places its emphasis on people's inherent motivational propensities for learning and growing, and how they can be supported" (p. 1). SDT argues that for people to be intrinsically motivated, they require support for their basic psychological needs, namely, autonomy, competence and relatedness. Therefore, to develop and maintain inner motivation, teachers need adequate autonomy and trust-that is, the freedom to implement practices that best meet the needs of their learners. They also need to feel competent-that is, possess the necessary skills and knowledge for the role and witness the positive impact of their instruction on students. They likewise need to experience a sense of relatedness-that is, generally maintain positive relationships with their students and colleagues (Ryan \& Deci, 2020). Factors that obstruct or prevent any of these three needs are seen to impact on a teacher's motivation and well-being negatively. These factors can include controlling education policies and administrators' leadership styles, poorly implemented reforms (Hargreaves, 2005), standardised practices and assessments (Moorhouse, 2018), students' behaviour, insufficient self-efficacy and career structures, and limited recognition or potential for professional development (Dörnyei \& Ushioda, 2011). SDT provides a framework to understand how educational or work settings either meet or frustrate these basic needs (Klassen et al, 2012; Ryan \& Deci, 2020). This framework is adopted in this study to analyse the impact ERT and the requirement for teaching synchronously online have had on university teachers' motivation and well-being.

\section{Teacher Motivation for Online Teaching}

With the dramatic expansion of online modes of teaching in higher education, researchers have begun to explore teacher motivation in contexts beyond the traditional classroom (e.g., Doon et al., 2020; Meyer, 2012; Wasilik \& Bolliger, 2009). Thus, research has reported that university teachers may be motivated to try online teaching by the challenge and a desire to implement innovative pedagogical approaches (e.g., Fredericksen et al., 2000). Their motivation in teaching online seems to depend on their perceptions of student learning and the quality of the online 
experience (Fredericksen et al., 2000). Wasilik and Bolliger (2009) found that teachers were generally satisfied with their online teaching experiences, valuing the flexibility of the format but frustrated by the lack of in-person interaction and technical difficulties. Meyer (2012) identified a complex mixture of personal factors (e.g., enjoying change and having young children) and professional factors (e.g., recognition and saving programmes with low enrolment) that influenced university teachers' motivation to offer courses online.

A recent mixed-method study by Doon et al. (2020) of university teachers' motivation to teach massive open online courses (MOOCs) corroborates the impression that their primary motivations are intrinsic. Specifically, they found teachers to be motivated by "interest in new learning technology, service to the public and community, desire to promote subject matter, and personal growth and development" (p. 39). They also found them to be frustrated with the lack of communication and interaction between themselves and their students.

\section{Emergency Remote Teaching}

The term ERT has emerged during the COVID-19 pandemic specifically as a way to differentiate between courses offered online in response to a crisis or disaster that would have typically been taught in-person, from courses that are intentionally designed for online instruction (Hodges et al., 2020). ERT is understood as a temporary measure to cover the period of crisis before the return to normality (Bozkurt \& Sharma, 2020). While online alternatives to in-person instruction have been deployed in response to national and regional crisis or disasters (e.g., Rush et al., 2016), COVID-19 is the first time ERT has been implemented on a global scale. The design and implementation of ERT measures are likely to be dependent on various contextual and human factors and related challenges. The teachers' and learners' access to technological resources, including high-speed internet, their readiness for online learning, the instructional support available, and policies mandated by institutions or governments all impact ERT (Hodges et al., 2020). In addition, teachers need to be able to adapt quickly to the radically different teaching and learning environment (Xie et al., 2019), while coping with the social and psychological effects of the crisis (American Psychological Society, 2020).

In Hong Kong, as with other contexts, ERT involved the use of synchronous online teaching (Moorhouse, 2020; Metscher et al., 2020). While providing benefits, synchronous online teaching can be demanding on the teacher who needs to teach and communicate content through a screen, engage learners using two-dimensional images, facilitate interactions in digital spaces, attend to students' emotional needs remotely, maintain a sense of presence in the absence of physical proximity, and troubleshoot technical problems (Rehn et al., 2018). In addition, the physical distance between the teacher and learner can make building relationships, an essential element of motivation (Klassen et al., 2012; Ryan \& Deci, 2020), more challenging (Rose \& Adams, 2014). The combined demands of ERT and the requirement to shift from the in-person to the synchronous online classroom are likely to have an impact on teacher motivation.

\section{The Study}

\section{Research Purpose and Question}

This study explores the effects of ERT and the requirement to conduct synchronous online teaching in response to COVID-19 on nine Hong Kong university EAP teachers' motivation after teaching exclusively online for a full semester. The study addresses the question:

(1) What impact has ERT, necessitated by COVID-19, had on EAP teachers' motivation?

To address the question, the nine participants from the selected university were interviewed in late May to early June 2020 after the spring semester had ended.

\section{Research Context}

The teachers interviewed for this study were working at an English language centre in one of Hong Kong's eight publicly funded universities. The university offers undergraduate and postgraduate programmes in a variety of disciplines; the majority of courses are taught exclusively in English. To support their transition to university and the English-language learning environment, all students take one credit-bearing EAP course in their first year of undergraduate studies intended to develop basic competencies in academic writing. Students also take other mandatory and optional EAP courses during their studies.

In late January 2020, as COVID-19 was starting to spread around the world, universities in Hong Kong decided to suspend in-person teaching to help contain the virus. This measure was at first temporary, but the ERT was extended for the full spring semester in March 2020 (Chan, 2020). The teachers in the current study were given 2 weeks to prepare for online teaching, which took the form of synchronous sessions delivered through VCS. The semester was extended for 2 weeks to make up for the preparation time, and workshops helped to prepare teachers for the new mode of teaching. 


\section{Participants}

The participants in this study taught EAP courses to undergraduate students of various majors. They were recruited for the project by the second author, an EAP teacher at the same university, and all agreed to participate. In total, four male and five female teachers were interviewed. The extent of their experience as EAP teachers ranged from 3 to 24 years. All held a master's degree, and one of them held a doctorate; they were assigned pseudonyms for this study. Before the COVID-19 outbreak, the teachers had a short experience of ERT in the first semester, due to the widespread civil unrest in Hong Kong, which led to the occupation of several university campuses. ERT, at that time, mainly involved the uploading of materials to the university LMS for student self-study. Previously, all the participants were engaged in in-person teaching and had no experience teaching exclusively online.

\section{Data Collection and Analysis}

Data were collected through individual, in-depth, semistructured interviews. The interviews were timed to allow the teachers to reflect on the full semester of experience with ERT. The interviews lasted 50-70 min each and were conducted using VCS to minimise person-to-person contact. Both researchers took part in all nine interviews. The interviews were audio-recorded to facilitate transcription. The semi-structured format for the interviews was adopted to facilitate an in-depth exploration of the participants' lived experiences and perceptions (Cohen et al., 2011) of ERT during COVID-19. An interview guide was created specifically for the study with questions regarding the participants' motivations for teaching EAP before the suspension of in-person teaching, their experiences with ERT, and their opinions about the suspension and the prospect of teaching online exclusively in future semesters (See Appendix 1 for the primary interview questions).

Qualitative data from the interviews were subjected to iterative thematic analysis (Braun \& Clarke, 2006) using SDT as an analytical framework. In the first stage, the transcriptions were read and re-read to familiarise the researchers with the data. Second, initial codes were generated and compared systematically on a shared Google Doc, then themes and subthemes were identified. At this stage, the researchers noticed that the data revealed two distinct groups within the dataset. The data were divided into two sets: one group that was positively affected by ERT $(n=5)$ and one group that was negatively affected by ERT $(n=4)$. These sets were labelled "thriving" and "surviving" based on the impact of ERT on their basic psychological needs. Next, the researchers reviewed the themes within each set and agreed on the final set. The themes were then compared to the SDT analytical framework (See Table 1.). Finally, extracts were selected, and the report was compiled. Throughout the process, the researchers maintained close communication to check understandings, ask for clarification, and discuss differences in interpretations before reaching a consensus (Cohen et al., 2011). Ethical approval for the study was provided at the university level with all participants giving informed consent.

\section{Findings}

The analysis of the data yielded two distinct answers to the research question regarding the impact of the shift to ERT, because of COVID-19, on EAP teachers' motivation. Five of the teachers thrived during ERT, reporting mainly positive effects on their motivation, while the other four reported primarily negative effects. In what follows, the data relating to the teachers' long-term motivation to teach before the shift to ERT are presented here first followed by the data relating to their motivation during ERT.

\section{The Teachers' Motivation Before ERT}

To understand the impact of COVID-19 and the shift to ERT on the participants' motivation, it is important first to understand their perceived motivation before the period of ERT and what factors impacted their motivation. All of the participants considered themselves to be motivated teachers committed to their profession before the shift. They attributed their motivation to the relationships that they formed with students and the sense that their instruction had been making a difference in their students' academic development and performance. Anderson, for example, talked about enjoying his job because of the effect that his teaching had on his students' performance:

I enjoy teaching. I've taught for a long time ... I enjoy taking students through the writing process from the beginning-choosing a topic, doing research, writing a first draft, revising it together, and producing the final draft; I think it is quite productive and quite worthwhile. ... [The students] were able to make drastic improvements. I'm quite pleased to say that motivates me as a teacher to see them doing well.

Tanya similarly attributed her motivation for teaching to her relationships with her students, and the "energy" that she felt when from working with them:

One of the key reasons I'm in teaching is because I really like working with groups of people. I get a lot 
Table 1 Final themes of the data analysis

\begin{tabular}{|c|c|c|}
\hline & $\begin{array}{l}\text { Thriving group } \\
\text { (Anderson, Anthony, Charlene, Eddy, and Jake) }\end{array}$ & $\begin{array}{l}\text { Surviving group } \\
\text { (Darcy, Kylie, Mandy, Tanya) }\end{array}$ \\
\hline The teachers' motivation before ERT & \multicolumn{2}{|c|}{$\begin{array}{l}\text { Motivated and committed to teaching } \\
\text { - Relationship with learners (Relatedness) } \\
\text { - Impact on students' academic development and performance (Competence) }\end{array}$} \\
\hline \multirow[t]{2}{*}{ The impact of ERT on teachers' motivation } & $\begin{array}{l}\text { Positive effect on motivation } \\
\text { - Reinvigorated teaching (Competence) }\end{array}$ & $\begin{array}{l}\text { Negative effect on motivation } \\
\text { - Questioned professional competence } \\
\text { (Competence) }\end{array}$ \\
\hline & - Develop new skills useful for career (Autonomy) & $\begin{array}{l}\text { - Hard to build rapport with learners } \\
\text { (Relatedness) } \\
\text { - Increased effort (Competence) }\end{array}$ \\
\hline Online vs. in-person teaching & $\begin{array}{l}\text { Preference for in-person over online teaching } \\
\text { - Relationship with learners (Relatedness) }\end{array}$ & \\
\hline
\end{tabular}

of energy from a group of people. ... [How] I feel about my job is heavily based on my ability to form relationships with my students, which I do just through incidence of chat $[s i c]$.

The other participants' motivations were similar. Eddy stated, "The relationship between me and the students motivates me". Kylie said that teaching "is very exciting, and I get a lot of energy from [students]. So, at the end of the class, I'm more awake than [at] the beginning". Darcy explained, "You know, [students] come in, and they don't know anything about academic writing, and, at least, by the end of the course ...we have succeeded in giving them a good step into the academic writing world".

In the present study, the perceived motivations of participants, before the shift to ERT, provided context for the impact of ERT on their motivation. This context can, in part, explain the distinctly different ways in which the shift to ERT impacted the teachers in this study.

\section{The Impact of ERT on Teachers' Motivation: Thriving and Surviving}

\section{Thriving During ERT}

Five of the participants-Anderson, Anthony, Charlene, Eddy, and Jake-reported positive effects of ERT on their motivation and seemed to thrive during the transition to online-only teaching. This "thriving" group expressed the belief that the experience had reinvigorated their teaching and provided them with new skills that could aid them in their careers going forward.

Anderson stated that, before COVID-19, his teaching had gone into "cruise mode", while online teaching was for him "something completely different and a new challenge" that caused him to re-think his course content, activities, and methods. Similarly, Eddy felt that he had been "more motivated this semester" because he had had to consider his learners' needs more carefully than before; thus, he developed a "step-by-step guide before each assessment to make sure they [the students] could follow what they are supposed to do during the assessment". Charlene spoke of having "more time" to devote to her teaching and being able to assign additional work to her learners that bolstered their academic performance. Jake saw the period of teaching online as an opportunity to reflect on his practice and think of new ways to engage learners; he also expressed a desire to create a sense of "normality" for students, and he was motivated to create a positive learning environment for them.

In addition to perceiving a positive impact of ERT on their teaching, Charlene, Eddy, and Jake thought that the skills that they had developed during the cessation of inperson classes had the potential to open up new career opportunities. For example, Eddy stated, "I think that helps build up the $\mathrm{CV}$ as well. Maybe because we all knew that the universities are thinking of going in this direction, and [the shift to online learning] has been in the cards for a number of years". Charlene felt she could now live anywhere in the world, and teaching students "anywhere in the world".

\section{Surviving ERT}

Four of the participants-Darcy, Kylie, Mandy, and Tanya-reported mainly negative effects of ERT on their motivation and, rather than thriving, seemed merely to have survived the shift to online teaching. The members of this "surviving" group stated that the new environment had caused them to question their professional competence, made it challenging to develop a rapport with learners, left 
them feeling exhausted, and sapped their satisfaction with or motivation to engage in teaching.

The challenges associated with ERT, including a steep learning curve, had eroded these teachers' self-confidence. Kylie, who considered herself to have been highly motivated before the shift to ERT, spoke of "this horrible feeling" of professional incompetence, describing teaching online as being "kind of like when you are first thrown into a classroom". Darcy similarly said that, when beginning online teaching, she had "really started from nothing". This sense of lacking competence frustrated the participants and was exacerbated by the difficulties they experienced trying to establish a rapport with their students online. Phrases such as "production-line teaching", "teaching into the void", and "disembodied voices on the other side [of those who] may or may not be paying attention" reflect this frustration. Adding to the problem was the fact that the students were not required to turn on their cameras during synchronous lessons, and very few did so-ostensibly owing to privacy issues. The students' blank screens became the norm in their classes. Darcy offered a telling anecdote in this regard: having encountered some of the students whom she had taught online in the real world, she was unable to recognise them:

I really didn't enjoy [online teaching] because there was a lack of personal connection [with learners]. I didn't have that same rapport. I definitely developed some rapport with students. I mean, a couple of them saw me last week on campus. I don't know how they recognised me. They came up to me and said, "Oh, you're our teacher". I had no idea because I don't know what they look like.

Such experiences increased the dissatisfaction of the members of the "surviving" group and sapped their motivation for the semester. Though most of them tried to remain motivated, after several weeks of online teaching, they found it difficult to do so. Tanya said that she had used various strategies at first to try to build a rapport with learners but that her effort had flagged as the weeks went by:

In the beginning [of ERT], I tried to ask students to join the class 10-15 min before the lesson starts, and I would have a flip chart up with a list of things for students to do ... and then I asked them to switch on their mic and tell me something about themselves. ... But then, I'll be honest, after about four lessons, I found it exhausting ... I couldn't sustain it for the whole course.

Darcy, Kylie, Mandy and Tanya all asserted that teaching online required a greater effort than teaching inperson. Tanya said that she had had to cut back on her efforts to retain her energy over the semester: "I became more emotionally exhausted and mentally exhausted, and I started cutting corners where I could because I knew I needed the energy to finish the semester". Kylie contrasted feeling "exhausted" at the end of an online class with feeling "energised" after a in-person class. The lack of interaction with colleagues, since they were encouraged to work from home, increased their sense of isolation.

\section{Online vs In-person Teaching}

While members of the "thriving" and "surviving" groups responded differently to ERT, all of the interviewees expressed a preference for in-person teaching. While those who thrived found aspects of online teaching appealing, such as the ease of organising and conducting one-on-one consultations, they still missed the physical and social environment of the traditional classroom. Many of the participants echoed Anthony's sentiment that online teaching "as an emergency measure is okay, but I wouldn't like the university to think that we can now provide all the courses online". Charlene stated, "I like online teaching a lot, but I feel there is something missing ... I do want to meet the students in person".

Unsurprisingly, members of the "surviving" group were eager to return to in-person lessons as soon as possible. Darcy shared her fear of the prospect of having to continue online teaching:

We don't want to [teach online]. ... I'm fine with the whole idea of blended learning and having some online teaching. But if someone told me that this is going to be my job for the future, forever, I would really have to reconsider my career. Because it was really draining sitting in front of a black screen for two or three hours at a time. Everything was teacherled. Everything was coming from me without getting any instant feedback. ... Now, I want to get back to the classroom.

It is noteworthy that Darcy expressed the intention to look for another career should the requirement for online-only teaching continue indefinitely, which shows the impact that ERT has had on her motivation as well as her sense of job satisfaction. Such attitudes are concerning, especially since Darcy, along with the rest of the participants, asserted that they had been motivated before the shift to ERT.

\section{Discussion and Conclusion}

The COVID-19 pandemic has brought immense challenges, with higher education being one of the most affected domains due to its reliance on in-person 
interactions (Hodges et al., 2020). Teachers have needed to find ways to support student learning and provide a sense of normality during these uncertain times (Crawford et al., 2020; Hodges et al., 2020). This approach has led to the implementation of ERT and, in many contexts, synchronous online teaching (Moorhouse, 2020; Metscher et al., 2020). Understandably, teachers around the world were not prepared for this rapid shift online (Wang, 2020). While technology in higher education has been a standard feature for several years, these technologies have tended to supplement in-person teaching (Deng \& Tavares, 2013). COVID-19 has meant that teachers have been required to teach exclusively online-bringing new and specific challenges (Bozkurt \& Sharma, 2020). This current study sought to understand the effect of ERT on university teachers' motivation. The small number of participants notwithstanding, the findings presented here suggest that teachers have responded to the shift to ERT in very different ways that have significant implications for their motivation in the synchronous online classroom.

Importantly, all the teachers interviewed expressed a high level of motivation in their regular teaching practices. Their motivation primarily came from their rapport with students and the positive impact they believe their instruction has on students' academic development. This motivation suggests that their teaching role fulfils the basic psychological needs of competence and relatedness (Ryan $\&$ Deci, 2020). Previous studies have likewise found university teachers to be motivated by their relationship that they form with students and the impact they have on students' academic development (Carson \& Chase, 2009; Han \& Yin, 2016).

However, ERT and the need to teach synchronously online had a positive effect on one group of teachers' motivations, labelled thriving, and a negative effect on the other group of teachers, labelled surviving. The members of the thriving group were reinvigorated and acquired new skills that could aid them in their careers. They seemed to relish the opportunity to try new teaching approaches and seem to get some success from their efforts. This success fulfilled their sense of mastery, the feeling that they can succeed and grow despite the challenges of ERT (Ryan \& Deci, 2020). They also valued the opportunity to develop new skills. This belief may have given them greater ownership over their actions while also increasing their sense of professional competence. These findings are similar to other studies that have explored teacher motivation for online teaching, seeing it as an opportunity to innovate and try something new (e.g., Wasilik \& Bolliger, 2009). Although teachers in previous studies tended to have selected to use online teaching modes by choice and were not forced to do so by a global pandemic.
The impact on the surviving group was radically different. This group questioned their professional competence, struggled to build rapport with learners, felt isolated, and struggled to gain any satisfaction from teaching. Their basic psychological needs of relatedness and competence were, therefore, unfulfilled (Ryan \& Deci, 2020). This lack of fulfilment seems to have led to a sense of emotional and physical exhaustion, with one teacher even suggesting leaving the profession. The use of VCS to teach synchronous online lessons seems to have the biggest negative effect on the teachers' motivation. Students not turning on the cameras and not actively engaging in the lessons made the teachers feel disconnected from learners. This lack of connectedness has been found in other research with online teachers (Rose \& Adams, 2014). As the teachers identified their relationship with the learners as one of their main motivators before the need for ERT, it is understandable that the loss of this relationship would impact them in such a way. In addition, teaching synchronously online requires specific skills (Rehn et al., 2018), which the teachers may not have felt they possessed, leading to the feeling of incompetence. Worryingly, previous studies have shown that if teachers' need for relatedness and competence are not met, this could reduce their engagement (Roth et al., 2007) and increase their emotional exhaustion (Klassen et al., 2012). This reaction does seem somewhat evident in the responses of the "surviving" group, with some members struggling to maintain the effort needed to teach online throughout the period of ERT.

Interestingly, all the participants wanted a return to inperson teaching. This desire seems to be primarily due to the need for relatedness (Ryan \& Deci, 2020). Therefore, while the thriving group may see short-term benefits to the chance to teach online, the need for relatedness makes inperson teaching more attractive in the long term. Although not explicitly discussed in the interviews, their preference for in-person teaching could be due in part to the feeling of connectiveness the teachers feel with the learners in the different modes, or social presence. Most research of social presence in online environments have explored whether students in online courses perceive those they are interacting with online are real people (Sung \& Mayer, 2012). However, due to the lack of learners' response and their practice of switching off cameras, this study may suggest that teachers lack a sense of social presence during synchronous online teaching. This could explain the frustrations evident in the thriving group, and the preference for in-person teaching of all the participants.

The factors that may predispose a teacher to thrive or merely survive are not clear in this study. There is a need to exploring the personal and professional factors, such as experiences, teaching strategies, and beliefs, that could affect whether a teacher survives or thrives during ERT. 
Still, this study indicates that teachers who are motivated in the traditional classroom do not necessarily maintain their motivation when forced by circumstances to transition to online teaching. Individual teachers have responded to the situation caused by COVID-19 in distinct ways. Significantly, though, even those who have thrived during ERT may struggle to maintain their motivation should the uncertainties caused by COVID-19 continue indefinitely (Wong \& Moorhouse, 2020).

Accordingly, universities, faculties, and department leaders need to recognise the factors that can affect teachers' intrinsic motivations, such as competence, autonomy, and relatedness (Ryan \& Deci, 2020) and together with teachers explore ways to facilitate the transition to online teaching. Teachers come to ERT equipped with various competencies, needs, and expectations, and understanding the differences among them is essential (Hodges et al., 2020; Wang, 2020). University leaders, for their part, should acknowledge the potential negative impacts of online teaching on teacher motivation and implement initiatives designed to prepare and support educators psychologically in addition to providing pedagogical and technological support. For the benefit of their students, teachers need to thrive rather than merely survive (Beltman et al., 2011).

Although this study has yielded valuable findings, it has limitations with respect to scale and methods. Thus, a more extensive study exploring the impact of ERT and other responses to and impacts of COVID-19 on teachers from various departments and in various contexts is warranted. In addition, the use of different research methods would be informative. Qualitative approaches are appropriate for an initial investigation in an emerging field, but a mixedmethod study combining qualitative and quantitative methods could yield more robust results. Furthermore, scholars should conduct observations of synchronous online lessons. Through exploring the interactions between the teacher and students, and the use of teaching strategies or technologies in the synchronous online classroom, we may better understand the conditions required for teachers to thrive during ERT.

\section{Appendix 1}

\section{Primary Interview Questions}

1. How would you describe your motivation to teach before the suspension of in-person classes? What factors influence your motivation to teach?

2. How has the suspension of in-person teaching and requirement to teach exclusively online affected your motivation to teach? If it has changed, what factors have influenced the change? If it has not, why not?

3. What could be done to increase your motivation to teach?

4. What are your thoughts on the possibility of teaching exclusively online in the future?

\section{References}

American Psychological Society. (2020). https://www.apa.org/practice/programs/dmhi/researchinformation/social-distancing

Beltman, S., Mansfield, C., \& Price, A. (2011). Thriving not just surviving: A review of research on teacher resilience. Educational Research Review, 6(3), 185-207.

Bozkurt, A., \& Sharma, R. C. (2020). Emergency remote teaching in a time of global crisis due to CoronaVirus pandemic. Asian Journal of Distance Education, 15(1), i-vi.

Braun, V., \& Clarke, V. (2006). Using thematic analysis in psychology. Qualitative Research in Psychology, 3(2), 77-101.

Carson, R. L., \& Chase, M. A. (2009). An examination of physical education teacher motivation from a self-determination theoretical framework. Physical Education and Sport Pedagogy, 14(4), $335-353$.

Chan, H-H. (2020). Coronavirus: Hong Kong students adapt to online learning amid class suspension over pandemic. SCMP Online. Retrieved March 16, 2020, from https://www.scmp.com/news/hong-kong/education/article/ 3075280/coronavirus-hong-kong-students-adapt-online-learningamid

Cohen, L., Manion, L., \& Morrison, K. (2011). Research methods in education. (7th ed.). Routledge.

Crawford, J., Butler-Henderson, K., Rudolph, J., Malkawi, B., Glowatz, M., Burton, R., Magni, P., \& Lam, S. (2020). COVID-19: 20 countries' higher education intra-period digital pedagogy responses. Journal of Applied Learning \& Teaching, 3(1), 1-20. https://doi.org/10.37074/jalt.2020.3.1.7.

Deng, L., \& Tavares, N. J. (2013). From Moodle to Facebook: Exploring students' motivation and experiences in online communities. Computers \& Education, 68, 167-176.

Doo, M. Y., Tang, Y., Bonk, C. J., \& Zhu, M. (2020). MOOC instructor motivation and career development. Distance Education, $\quad 41(1), \quad 26-47$. https://doi.org/10.1080/01587919.2020.1724770.

Dörnyei, Z., \& Ushioda, E. (2011). Teaching and researching motivation. (2nd ed.). Longman.

Fredericksen, E., Pickett, A., Shea, P., Pelz, W., \& Swan, K. (2000). Factors influencing faculty satisfaction with asynchronous teaching and learning in the SUNY learning network. Journal of Asynchronous Learning Networks, 4(3), 245-278.

Han, J., \& Yin, H. (2016). Teacher motivation: Definition, research development and implications for teachers. Cogent Education. https://doi.org/10.1080/2331186X.2016.1217819.

Hargreaves, A. (2005). Educational change takes ages: Life, career and generational factors in teachers' emotional responses to educational change. Teaching and teacher Education, 21(8), 967-983.

Hodges, C., Moore, S., Lockee, B., Trust, T., \& Bond, A. (2020). The difference between emergency remote teaching and online learning. Educause Review Online. Retrieved March 27, 2020, from: 
https://er.educause.edu/articles/2020/3/the-difference-betweenemergency-remote-teaching-and-online-learning

Klassen, R. M., Perry, N. E., \& Frenzel, A. C. (2012). Teachers' relatedness with students: An underemphasized component of teachers' basic psychological needs. Journal of Educational Psychology, 104(1), 150.

Martin, F., \& Parker, M. A. (2014). Use of synchronous virtual classrooms: Why, who, and how. MERLOT Journal of Online Learning and Teaching, 10(2), 192-210.

Metscher, S. E., Tramantano, J. S., \& Wong, K. M. (2020). Digital instructional practices to promote pedagogical content knowledge during COVID-19. Journal of Education for Teaching. https://doi.org/10.1080/02607476.2020.1842135.

Meyer, K. A. (2012). The influence of online teaching on faculty productivity. Innovative Higher Education, 37(1), 37-52.

Moorhouse, B. L. (2018). Standardized homework practices and teacher autonomy: Experiences of primary english language teachers in Hong Kong. The Asia-Pacific Education Researcher, 27(5), 345-354.

Moorhouse, B. L. (2020). Adaptations to a face-to-face initial teacher education course 'forced' online due to the COVID-19 pandemic. Journal of Education for Teaching, 46(4), 609-611.

Rehn, N., Maor, D., \& McConney, A. (2018). The specific skills required of teachers who deliver $\mathrm{K}-12$ distance education courses by synchronous videoconference: Implications for training and professional development. Technology, Pedagogy and Education, 27(4), 417-429.

Rose, E., \& Adams, C. (2014). Will I ever connect with the students?" Online Teaching and the Pedagogy of Care. Phenomenology \& Practice, 8(1), 5-16.

Roth, G., Assor, A., Kanat-Maymon, Y., \& Kaplan, H. (2007). Autonomous motivation for teaching: How self-determined teaching may lead to self-determined learning. Journal of Educational Psychology, 99, 761-774.
Rush, S. C., Partridge, A., \& Wheeler, J. (2016). Implementing emergency online schools on the fly as a means of responding to school closures after disaster strikes. Journal of Educational Technology Systems, $\quad 45(2), \quad$ 188-201. https://doi.org/10.1177/0047239516649740.

Ryan, R. M., \& Deci, E. L. (2000). Intrinsic and extrinsic motivations: Classic definitions and new directions. Contemporary educational psychology, 25(1), 54-67.

Ryan, R. M., \& Deci, E. L. (2020). Intrinsic and extrinsic motivation from a self-determination theory perspective: Definitions, theory, practices, and future directions. Contemporary Educational Psychology. https://doi.org/10.1016/j.cedpsych.2020.101860.

Sung, E., \& Mayer, R. E. (2012). Five facets of social presence in online distance education. Computers in Human Behavior, 28(5), $1738-1747$.

Wang, C. X. (2020). CAFE: An Instructional Design Model to Assist K-12 Teachers to Teach Remotely during and beyond the Covid19 Pandemic. TechTrends. https://doi.org/10.1007/s11528-020-00555-8.

Wasilik, O., \& Bolliger, D. U. (2009). Faculty satisfaction in the online environment: An institutional study. Internet and Higher Education, 12(3-4), 173-178.

Wong, K. M., \& Moorhouse, B. L. (2020). The impact of social uncertainty, protests, and COVID-19 on Hong Kong teachers. Journal of Loss and Trauma, 25(8), 649-655.

Xie, K., Heddy, B. C., \& Vongkulluksn, V. W. (2019). Examining engagement in context using experience-sampling method with mobile technology. Contemporary Educational Psychology, 59, 101788.

Publisher's Note Springer Nature remains neutral with regard to jurisdictional claims in published maps and institutional affiliations. 